\title{
Annual variations in the number of malaria cases related to two different patterns of Anopheles darlingi transmission potential in the Maroni area of French Guiana
}

\author{
Florence Fouque ${ }^{* 1}$, Pascal Gaborit ${ }^{\dagger 2}$, Romuald Carinci ${ }^{\dagger 2}$, Jean Issaly ${ }^{\dagger 2}$ and Romain Girod ${ }^{+2}$
}

\begin{abstract}
Background: With an Annual Parasite Incidence (API) of 132.1, in the high and moderate risks zones, the Maroni area of French Guiana has the second highest malaria incidence of South-America after Guyana (API = 183.54) and far above Brazil (API = 28.25). Malaria transmission is occurring despite strong medical assistance and active vector control, based on general WHO recommendations. This situation is generated by two main factors that are the social and cultural characteristics of this border area, where several ethnic groups are living, and the lack of understanding of transmission dynamics of the main mosquito vector, Anopheles darlingi. In this context, entomological data collected in two villages belonging to two different ethnic groups of the French border of the Maroni River, were retrospectively analysed to find out how the mosquito bionomics are related to the malaria transmission patterns.
\end{abstract}

Methods: Data were provided by human landing catches of mosquitoes carried out each month for two years in two villages belonging to two ethnic groups, the Amerindians Wayanas and the Aloukous of African origin. The mosquitoes were sorted by species, sex, date, hour and place of collection and processed for Plasmodium sp. parasite detection. The data were compiled to provide the following variables: human biting rates (HBR), parity rates (PR), numbers of infective bites (IB), entomological inoculation rates (EIR) and numbers of infected mosquitoes surviving enough to transmit (IMT). Spatial and temporal differences of variables between locations and during the night were tested by the Kruskall-Wallis analysis of variance to find out significant variations.

Results: The populations of the main mosquito vector An. darlingi showed significant variations in the spatial and temporal HBR/person/night and HBR/person/hour, IB/person/month and IB/person/hour, and IMT/village/night and IMT/village/hour. In the village of Loca (Aloukous), the IMT peaked from June to August with a very low transmission during the other months. The risks were higher during the first part of the night and an EIR of 10 infective bites per person and per year was estimated. In the village of Twenke (Wayanas), high level of transmission was reported all year with small peaks in March and October. The risk was higher during the second part of the night and an EIR of 5 infective bites per person and per year was estimated.

Conclusion: For the first time in the past 40 years, the mosquito bionomics was related to the malaria transmission patterns in French Guiana. The peak of malaria cases reported from August to October in the Maroni region is concomitant with the significant peak of An. darlingi IMT, reported from the village of Loca where transmission is higher. However, the persistent number of cases reported all year long may also be related to the transmission in the Amerindian villages. The An. darlingi bionomics for these two close populations were found significantly different and may explain why a uniform vector control method is inadequate. Following these findings, malaria prevention measures adapted to the local conditions are needed. Finally, the question of the presence of An. darlingi sub-species is raised.

(C) 2010 Fouque et al; licensee BioMed Central Ltd. This is an Open Access article distributed under the terms of the Creative Commons BHoMed Central Attribution License (http://creativecommons.org/licenses/by/2.0), which permits unrestricted use, distribution, and reproduction in any medium, provided the original work is properly cited. 


\section{Background}

With about 4,000 cases of malaria annually [1] and an annual parasite incidence (API) of 132.1 in the high and moderate risks zones, the Maroni area of French Guiana has the second highest malaria incidence of South-America, after Guyana (API $=183.59)$ and far higher than Brazil $(\mathrm{API}=25.23)$ [2]. Malaria transmission is reported mostly from the Maroni and Oyapock regions with almost no transmission in the main city of Cayenne and low number of cases in the coastal areas [3,4]. A first control of the disease was successfully maintained between the 1950s and the 1970s, due to DDT sprayings [5]. Plasmodium indices dropped from $26.1 \%$ in 1949 to $0.9 \%$ in 1952 [6-8]. Then, malaria incidence increased from 117 cases and an incidence of 2.3 per 1,000 in 1970 [7] to 3,349 cases and an incidence of 38.5 per 1,000 in 1987 [9]. A peak of about 6,000 malaria cases was reached in 1989 and again in 1995 [10]. Until the year $2005,90 \%$ of the malaria cases were due to Plasmodium falciparum [9-11], but then a change was reported with $50 \%$ of the cases due to Plasmodium vivax $[11,12]$. The possible reasons for such an increase in the malaria incidence are numerous, such as mosquito resistance to insecticides, parasite resistance to anti-malarial drugs, population movements due to political reasons or gold mining, but also changes in the biting behavior of the main mosquito vector Anopheles (Nyssorhynchus) darlingi $[3,5,10]$.

Since the first studies on the vectors of malaria in French Guiana, the species An. darlingi was reported as the main and sometimes the exclusive vector $[6,13,14]$. Anopheles darlingi is widely distributed in different ecological systems of French Guiana [14,15]. Other species, such as Anopheles (Nyssorhynchus) aquasalis, Anopheles (Nyssorhynchus) braziliensis, Anopheles (Nyssorhynchus) nuñeztovari, Anopheles (Kerteszia) neivai and Anopheles (Nyssorhynchus) oswaldoi are also present in French Guiana [15]. The bionomics of An. darlingi in the coastal areas of French Guiana were studied during the late 1970s and showed an exophilic biting preference with tri-modal biting peaks around 6:00 PM, 1:00 AM to 2:00 AM and around sunrise at 7:00 AM [13]. However, very little is known about the indoor resting behaviour of An darlingi and the few studies that have been done report all night indoor resting in Brazil [16] to only two to three hours indoor resting in Surinam [17]. Recent entomological investigations in two different areas of the Maroni River reported a great behavioural heterogeneity, but no relationship could be found between $A n$. darlingi parameters and malaria transmission [18,19].

\footnotetext{
* Correspondence: florence.fouque@pasteur.fr

${ }^{1}$ Institut Pasteur, Cellule d'Intervention Biologique d'Urgence (CIBU), 25-28, rue du Dr Roux, 75724 Paris cedex 15, France

† Contributed equally

Full list of author information is available at the end of the article
}

The "Service Départemental de Démoustication" (SDD) is in charge of malaria prevention and vector control in French Guiana. Malaria cases detection is based on examination of blood smears from febrile patients and vector control consists of chemical spraying of houses and dependences $[3,4,11,14]$. Some impregnated bed-nets campaigns are attempted regularly, but do not reached the required level in the populations at risks. Because the data available on the bionomics of the malaria vector An. darlingi inside the Amazonian forest of French Guiana, such as the biting activity and infection rate, could not be related to malaria transmission $[18,19]$, it appears very difficult to decide which vector control measures are best adapted to the situation. Furthermore, the populations living in the Maroni region have strong ethnic, cultural and social differences, and a unique vector control strategy may not be applicable to every local situation. In this context, a retrospective analysis of entomological data collected during long-term studies of the malaria transmission risks carried out along the Maroni River is presented. The data were collected in two locations each with populations belonging to two different ethnic groups. Biting rates, parity and transmissions risks for $P$. falciparum, $P$. vivax and $P$. malariae were determined monthly over a two-year period in an "African-type" village and an Amerindian village. The results are then discussed according to recently published malaria transmission data and vector control options.

\section{Methods \\ Study sites}

The mosquito collections were performed in Loca and Twenke villages situated along the Maroni River (Figure 1). The village of Loca (latitude $3^{\circ} 49^{\prime} 27^{\prime \prime} \mathrm{N}$, longitude $\left.54^{\circ} 11^{\prime} 33^{\prime \prime} \mathrm{W}\right)$ is located at about two hours by boat and 30 $\mathrm{km}$ north from the main city of Maripasoula and has a population belonging to the ethnic group of Bonis/Aloukous, an African-type population, escaped from Dutch slavery two centuries ago. The village is composed of about 30 houses and is inhabited by about 100 persons, mostly women and children because the men are often working outside. The housing in Loca is heterogeneous with modern houses and old-style houses with disjointed woodcut. The village of Loca is known as a P. falciparum malaria focus. The village of Twenke (latitude $3^{\circ} 22^{\prime} 15^{\prime \prime} \mathrm{N}$, longitude $54^{\circ} 03^{\prime} 35^{\prime \prime} \mathrm{W}$ ) is situated at about $30 \mathrm{~km}$ south of Maripasoula (Figure 1), in an area inhabited by Amerindians belonging to the Wayanas ethnic group. The village has about 20 houses and is inhabited by about 150 persons from all ages who live in family groups. The housing of this village is traditional Amerindian with wooden stilts houses one storey high, no walls in the basement, and sometimes just two walls on the first floor. The village of Twenke is a malaria focus where both $P$. falciparum and $P$. vivax have been reported. 


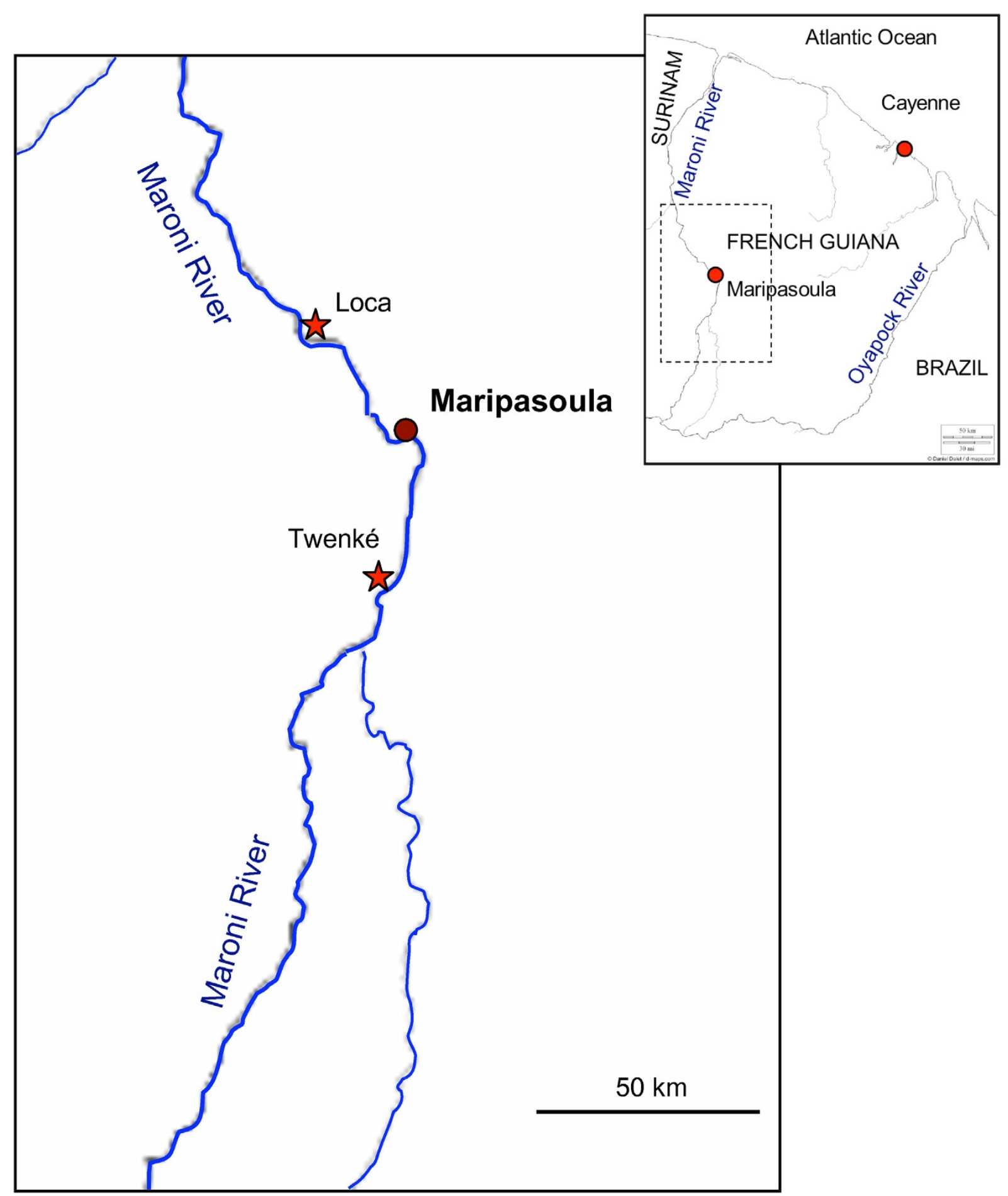

Figure 1 Study sites. Simplified map of the upper Maroni River (in dark blue) with the Aloukou village of Loca (north of the main town of Maripasoula), and the Amerindian village of Twenke (south of Maripasoula). 


\section{Mosquito captures}

Human landing catches [20] were carried out in each location by two persons from 6:30 PM to 0:30 AM, and 2 persons from $0: 30 \mathrm{AM}$ to $6: 30 \mathrm{AM}$. The teams were regularly rotated to avoid collection bias. The starting and ending collection hours were chosen according to the dusk and sunshine hours. The collections were made outside in the verandas of schools and/or community houses, having no people at night and situated in the middle of the villages. The collections were performed monthly during two consecutive nights in each village, beginning in March 1998 and ending in December 1999.

\section{Treatment of mosquitoes}

Females were identified and counted by species and sex the following morning with a field stereoscope. For each location, species, and hour, 10 females (or less) were dissected and the ovaries observed to determine the parity rates [21]. Mosquitoes were held desiccated individually into micro tubes with a record of species, sex and time of capture for later processing to determine their infection status. The head and thorax of each mosquito was then placed in a single tube, triturated in PBS and centrifuged at 3,000 rpm. The supernatant was then placed in an ELISA plate to detect the presence of Plasmodium antigen in the salivary glands. The Plasmodium detection by ELISA was based on the circumsporozoite protein detection [22] for the three Plasmodium species reported from the areas under survey. The following four strains of Plasmodium were tested: one strain of $P$. falciparum, two strains of $P$. vivax, ( $P$. vivax -210 and $P$. vivax-247) and one strain of $P$. malariae.

\section{Estimation of the numbers of infected mosquitoes surviving enough to transmit}

The survival of the females collected under field conditions was estimated from the monthly mean proportion of parous females according to the formula using the gonotrophic cycle mean duration $[23,24]$. Very few data are available on the duration of the gonotrophic cycle of An. darlingi. An average value of 2.3 days was obtained under field conditions in Brazil [25], but the gonotrophic cycle duration can vary from 2.4 to 4.4 days for the same species and from 2 to 5 days for Nyssorhynchus species [26]. Unpublished laboratory observations showed that the gonotrophic cycle of $A n$. darlingi in French Guiana varied between three and four days. Thus a mean value of 3.5 days was considered a good approximation. The survival estimates were then used to calculate the number of infected mosquitoes able to transmit (IMT), that is having a life duration longer than the duration of the extrinsic amplification. This IMT number was derived from the entomological parameters of the basic case reproductive rate defined by MacDonald [27] and used for vectorial capacity as developed by Garrett-Jones et al
[28]. The IMT number is calculated according to this simple equation:

$$
\mathrm{IMT}=\mathrm{HBR} \cdot\left(\mathrm{p}^{\mathrm{n}}\right) \cdot \mathrm{b}
$$

and was chosen because it can be estimated with only four variables, including the HBR [28], the survival (p) [27], the proportion of infected mosquitoes (b) and the duration of extrinsic incubation (n) [27,29,30]. The first three variables were available from the field data and the estimation of $b$ was a mean annual value for each location. The duration of the extrinsic incubation period (EIP) of the Plasmodium species in the mosquito An. darlingi has not been investigated, thus this variable was estimated through a logarithmic function with data reported for the sporogonic cycle of $P$. falciparum according to different temperatures $[31,32]$. The final value of the IMT was estimated per village on the base of 100 people in each village.

\section{Statistical analysis}

Continuous data were collected and to avoid bias in the distribution of the data into artificial classes, the normality of the data was not tested. The significance of the inter-groups differences among monthly and hourly variables was tested for each location with a non-parametric Analysis of Variance (ANOVA) according to the Kruskal-Wallis test with tied ranks [33]. The single factor analysis of variance was chosen because of unequal cell sizes [34]. Ranking of the values was made according to the Mann-Whitney test with tied ranks [35]. The statistical analyses were performed per month and per hour on the human biting rates (HBR), the parity rates (PR), the numbers of infective bites (IB) and the IMT. Raw data were used for monthly comparisons and monthly means were used for hourly comparisons.

\section{Climatic data}

The mean monthly rainfalls, maximum and minimum temperatures reported for the nearest town of Maripasoula (Figure 1) were provided by the National Oceanic and Atmospheric Administration (NOAA) through their website. The mean monthly flows of the Maroni River at Maripasoula, observed between 1953 and 2003, were extracted from the unpublished report "Régime hydrologique des fleuves guyanais: Etude fréquentielle des débits" provided by the Direction de l'Environnement from French Guiana.

\section{Epidemiological data}

The data were provided by the Institute of Health Surveillance (InVS) [11].

\section{Ethics}

The methodology for the mosquito captures was approved by the ethical committee of the Direction Départementale des Affaires Sanitaires et Sociales (DDASS) of French Gui- 
ana, representing the French Ministry of Health. The persons collecting mosquitoes were legally appointed by the Institut Pasteur of French Guiana and had salaries and access to all health care protection provided to the Institut Pasteur dependents.

\section{Results}

Annual variations of the Human Biting Rates (HBR)

From March 1998 to December 1999, 42 field trips were carried out in the villages of Loca and Twenke. The collections included 83 nights and 166 nights-men captures, and yielded a total of 5,187 Anopheles. The detailed data are reported in the Additional file 1. The captures gathered 5,182 (99.9\%) An. darlingi, three An. nuñez-tovari (0.05\%), one Anopheles (Anopheles) intermedius (0.02\%) and one non-identified Anopheles species. In the two years of the study, almost twice as many An. darlingi were captured in Twenke $(3,590)$ than in Loca $(1,597)$. The HBR of An. darlingi was highly variable during the year with a marked seasonality (Figure 2). In Loca, the collections yielded a mean number of 20.17 bites/person/night and an annual 8,126 bites/person/year, with a minimum of 0.13 females/person/ night in March 1998 and a maximum of 90 females/person/ night in June 1999. In Twenke, the collections yielded a mean number 46.18 bites/person/night and an annual $16,355 \mathrm{bites} /$ person/year, with a minimum of 6.13 females/ person/night in March 1998 and a maximum of 126.75 females/person/night in March 1999. The patterns were different between the two villages and also between the two years (Figure 2). In Loca, An. darlingi HBR peaked significantly in June, July and August (Table 1). In Twenke, mosquitoes where collected in high number all year with important year to year variation, the highest values were reported in April and May 1998 and in March 1999 with no significant peaks (Table 1). No data were available on the rainfalls in the locations of Loca and Twenke, but the mean monthly rainfalls reported from Maripasoula (Figure 1) shows that the mean monthly mosquito numbers were found around the rainy season, in June in Loca and from March to May in Twenke, and the lowest mean monthly numbers were found during the dry season from September to November (Figure 3). Furthermore, the peaks of HBR found from March to June could be linked to the Maroni River level (Figure 2). The An. darlingi HBRs were thus varying with the rainfalls and the Maroni River water level. The mean monthly numbers of malaria cases reported in






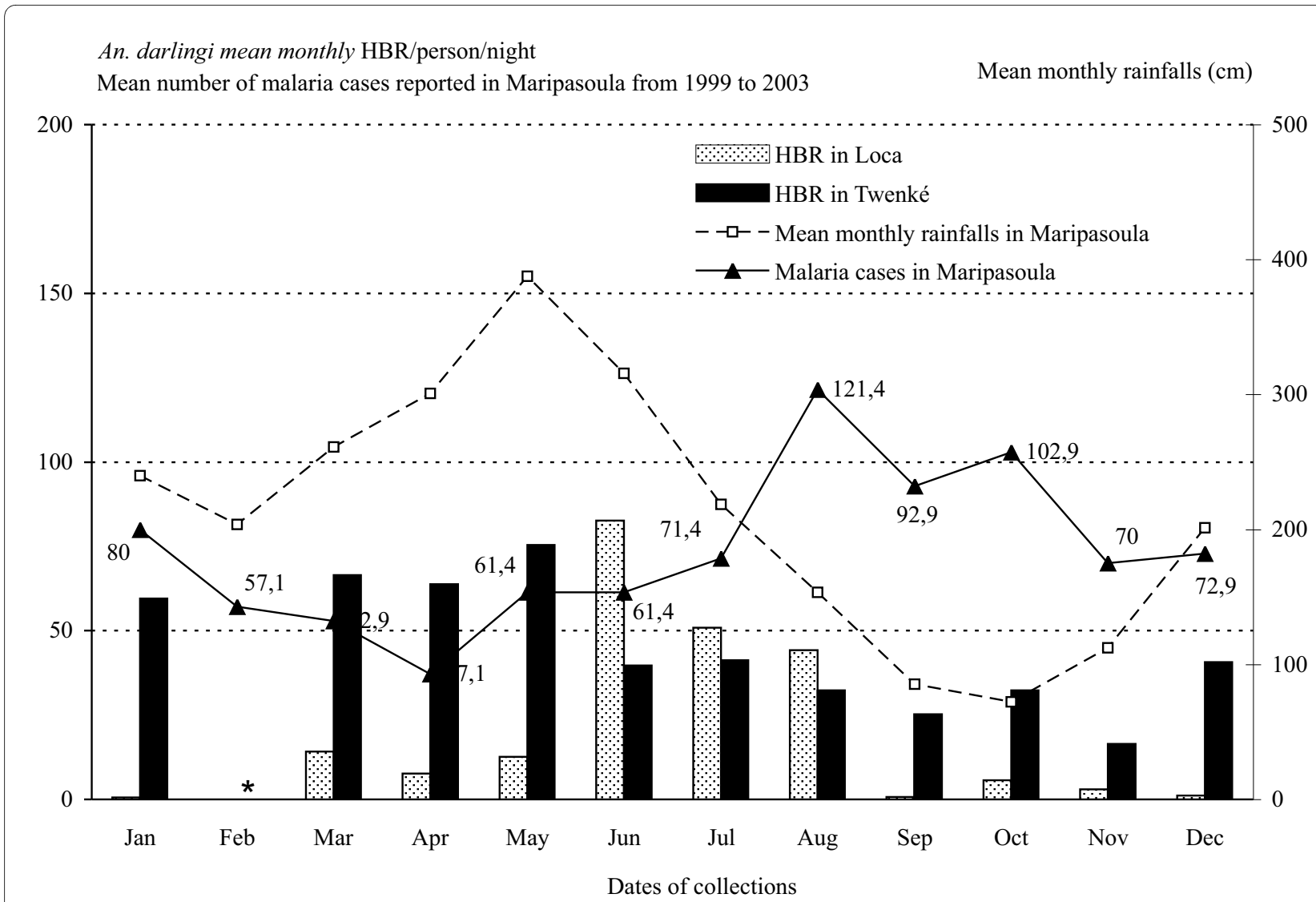

Figure 3 Monthly means of HBR/person/nigh. Monthly means of An. darlingiHBR/person/night (Human Biting Rates) in Loca and Twenke, and fluctuations of the monthly means rainfalls in Maripasoula, and the monthly mean numbers of malaria cases reported from Maripasoula. No captures were done for the months of February $\left({ }^{*}\right)$.

Maripasoula for the years 1999 to 2003 [11] show that malaria transmission peaks from August to October, i.e. at the beginning of the dry season when the HBRs are at their lowest values (the lowest HBRs are found from September to January in Loca and from September to November in Twenke), and has a minimum in April at the beginning of the rainy season (Figure 3).

\section{Annual variations of parity rates (PR)}

A total of 2,713 females of An. darlingi were dissected and the parity rates fluctuated between locations and years (Figure 4). In Loca, the monthly mean parity rate was $48.73 \%$, varying from $20 \%$ to $77.03 \%$. In Twenke, the monthly mean parity rate was $59.96 \%$, varying from $35.56 \%$ to $76.92 \%$. The percentage of parous females is a function of the mosquito survival under natural conditions. Although, no significant variations were estimated (Table 1), the female survival seems a little higher at the beginning of the year for both locations, slightly drops during the rainy season to reach a minimum in May-June, and increases again in August during the dry season (Figure 5).

\section{Night biting activity}

The mean HBRs/person/hour show different patterns in the two villages (Figure 6). In Loca, a mean number of 1.54 bites/person/hour was reported, varying from 0.67 bites/ person/hour to $2.32 \mathrm{bites} /$ person/hour. The mosquito aggressiveness increases slowly during the first part of the night until 2:00 AM, however the peaks were not significant (Table 1). In Twenke, a mean number of 3.65 bites $/$ person/hour was reported, varying from $1.83 \mathrm{bites} /$ person/hour to $5.66 \mathrm{bites} /$ person/hour. The mosquito aggressiveness increases rapidly and significantly during the first part of the night and reaches a peak at 10:00 PM (Table 1, Figure 6). The parity rates of the females were also fluctuating during the night but the patterns were completely similar in both locations, with a lowest percentage of parous females in Loca all night (Figure 6). The peaks of parity observed at 9:00 PM and 5:00 AM were not significant (Table 1).

\section{Mosquito infection rates and Entomological Inoculation Rates (EIR)}

The 5,187 An. darlingi collected were tested for their infection status and three P. falciparum strains were detected, 
Table 1: Results of the Kruskal-Wallis Analysis of Variance with tied ranks.

\begin{tabular}{|c|c|c|c|c|c|c|c|c|c|c|}
\hline Variables & Location & $\mathbf{N}$ & $\mathbf{H}$ & Sum $T$ & C & Ho & DF & Chi-2, 0.05 & $\mathbf{P}$ & Result \\
\hline \multirow{2}{*}{$\begin{array}{l}\text { Monthly } \\
\text { means } \\
\text { HBR/ } \\
\text { person/ } \\
\text { night }\end{array}$} & Loca & 38 & 31.94 & 450 & 0.9918 & 32.20 & 10 & 18.307 & $0.005<P<0.01$ & Reject Ho \\
\hline & Twenk & 41 & 13.79 & 18 & 0.9997 & 13.79 & 10 & 18.307 & $0.005<P<0.01$ & $\begin{array}{c}\text { Do not } \\
\text { reject Ho }\end{array}$ \\
\hline \multirow[t]{2}{*}{$\begin{array}{l}\text { Monthly } \\
\text { means PR }\end{array}$} & Loca & 28 & 11.01 & 406 & 0.9978 & 11.03 & 9 & 16.919 & $0.005<\mathrm{P}<0.01$ & $\begin{array}{c}\text { Do not } \\
\text { reject Ho }\end{array}$ \\
\hline & Twenk & 40 & 13.34 & 30 & 0.9995 & 13.34 & 10 & 18.307 & $0.005<\mathrm{P}<0.01$ & $\begin{array}{c}\text { Do not } \\
\text { reject Ho }\end{array}$ \\
\hline \multirow{2}{*}{$\begin{array}{l}\text { Means } \\
\text { HBR/ } \\
\text { person/ } \\
\text { hour }\end{array}$} & Loca & 24 & 13.41 & 18 & 0.9987 & 13.43 & 11 & 19.675 & $0.005<\mathrm{P}<0.01$ & $\begin{array}{c}\text { Do not } \\
\text { reject Ho }\end{array}$ \\
\hline & Twenk & 24 & 21.94 & 6 & 0.9996 & 21.95 & 11 & 19.675 & $0.005<P<0.01$ & Reject Ho \\
\hline \multirow[t]{2}{*}{$\begin{array}{l}\text { Means PR/ } \\
\text { hour }\end{array}$} & Loca & 24 & 6.46 & 24 & 0.9983 & 6.47 & 11 & 19.675 & $0.005<\mathrm{P}<0.01$ & $\begin{array}{l}\text { Do not } \\
\text { reject Ho }\end{array}$ \\
\hline & Twenk & 24 & 10.24 & 101 & 0.9927 & 10.31 & 11 & 19.675 & $0.005<\mathrm{P}<0.01$ & $\begin{array}{c}\text { Do not } \\
\text { reject Ho }\end{array}$ \\
\hline \multirow{2}{*}{$\begin{array}{l}\text { Monthly } \\
\text { means IB/ } \\
\text { person }\end{array}$} & Loca & 38 & 31.94 & 114 & 0.9979 & 32.00 & 10 & 18.307 & $0.005<P<0.01$ & Reject Ho \\
\hline & Twenk & 41 & 13.46 & 18 & 0.9997 & 13.79 & 10 & 18.307 & $0.005<\mathrm{P}<0.01$ & $\begin{array}{c}\text { Do not } \\
\text { reject Ho }\end{array}$ \\
\hline $\begin{array}{l}\text { Monthly } \\
\text { means IMT/ } \\
\text { night/ } \\
\text { village }\end{array}$ & Loca & 38 & 31.74 & 18 & 0.9997 & 31.75 & 10 & 18.307 & $0.005<P<0.01$ & Reject Ho \\
\hline
\end{tabular}


Table 1: Results of the Kruskal-Wallis Analysis of Variance with tied ranks. (Continued)

\begin{tabular}{|c|c|c|c|c|c|c|c|c|c|c|}
\hline & Twenk & 41 & 11.14 & 0 & 1.0000 & 11.14 & 10 & 18.307 & $0.005<\mathrm{P}<0.01$ & $\begin{array}{c}\text { Do not } \\
\text { reject Ho }\end{array}$ \\
\hline \multirow{2}{*}{$\begin{array}{l}\text { Means IB/ } \\
\text { person/ } \\
\text { hour }\end{array}$} & Loca & 24 & 13.41 & 18 & 0.9987 & 13.43 & 11 & 19.675 & $0.005<\mathrm{P}<0.01$ & $\begin{array}{l}\text { Do not } \\
\text { reject Ho }\end{array}$ \\
\hline & Twenk & 24 & 21.95 & 6 & 0.9996 & 21.95 & 11 & 19.675 & $0.005<P<0.01$ & Reject Ho \\
\hline \multirow{3}{*}{$\begin{array}{l}\text { Means IMT/ } \\
\text { village/ } \\
\text { hour }\end{array}$} & Loca & 24 & 18.30 & 0 & 1.0000 & 18.30 & 11 & 19.675 & $0.005<P<0.01$ & $\begin{array}{l}\text { Do not } \\
\text { reject Ho }\end{array}$ \\
\hline & & & & & & & & 17.275 & $0.01<\mathrm{P}<0.025$ & Reject Ho \\
\hline & Twenk & 24 & 21.34 & 0 & 1.0000 & 21.34 & 11 & 19.675 & $0.005<P<0.01$ & Reject Ho \\
\hline
\end{tabular}

Results of the Kruskal-Wallis Analysis of Variance with tied ranks for the following variables: the Monthly means HBR/person/night, the monthly means PR, the means HBR/person/hour, the means PR/hour, the monthly means IB/person, the monthly means IMT/night/village, the means IB/person/hour and the means IMT/village/hour. 


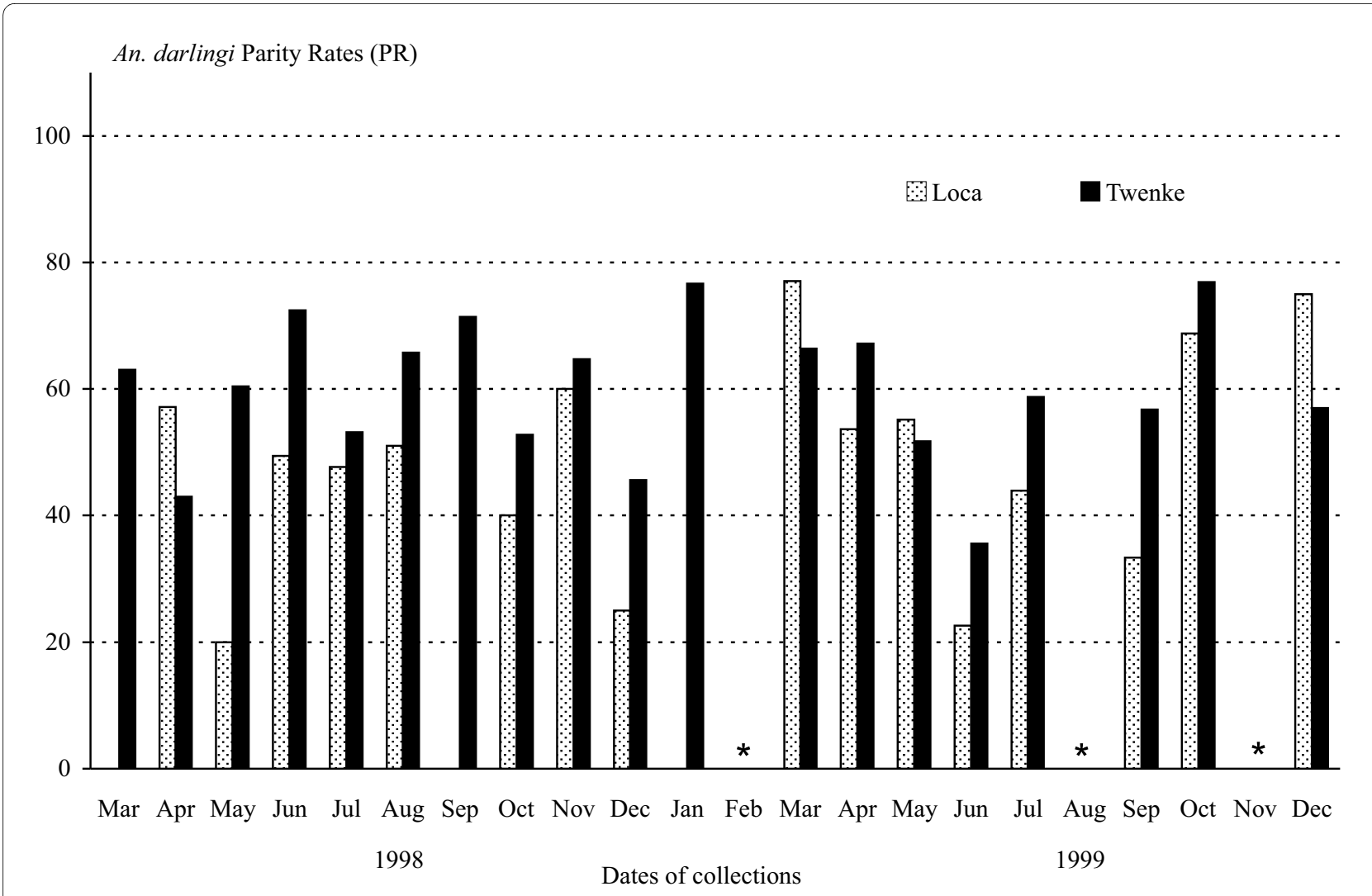

Figure 4 Field Parity Rates. Anopheles darlingi PR (Parity Rates) estimated from the field collections in Loca and Twenke from March 1998 to December 1999. No captures were done for the months of February, August and November $1999\left(^{*}\right)$.

two from Loca and one from Twenke. The P. falciparum reported from Loca were found in females collected between 1:30 AM and 2:30 AM on the $16^{\text {th }}$ July 1998 , and between 8:30 PM and 9:30 PM on the 24th of April 1999. The strain from Twenke was reported from a female collected between 5:30 AM and 6:30 AM on the $10^{\text {th }}$ of July 1999. The overall infection rate was $0.58 / 1000$ with an infection rate of $1.25 / 1,000$ in Loca and $0.28 / 1,000$ in Twenke. The entomological inoculation rate (EIR) was 10 infective bites/person/year and 5 infective bites/person/ year, in Loca and Twenke, respectively. The mean numbers of infective bites/person during the year varies according to the number of bites (Figure 7) with a significant peak from June to August in Loca (Table 1). High numbers of infective bites were found all year in Twenke (Figure 7) with a non-significant peak from March to May (Table 1). The hourly patterns observed during the night are also based on the biting numbers (Figure 8) with a non-significant peak at 2:00 AM in Loca and a significant peak between 10:00 PM and 2:00 AM in Twenke (Table 1). For both locations, it is worthwhile to note that the number of infective bites was multiplied by three during the peak.

\section{Numbers of infected Mosquitoes surviving enough to Transmit (IMT) and transmission risks}

The An. darlingi IMT fluctuated greatly and significantly monthly and hourly in both villages (Figures 7 and 8, Table 1). In Loca, the IMT peaks significantly in August and during the second part of the night between 1:00 AM and 3:00 AM (Figures $7 \& 8$ ). The transmission risk increases slowly after 9:00 PM until 2:00 AM and decreases until the morning. In Twenke, the IMT peaks in March and October (Figure 7) and significantly the first part of the night, between 9:00 PM and 2:00 AM (Figure 8). In Twenke, the transmission risk increases rapidly during the first part of the night and remains high for a few hours, than decreases slowly the second part of the night. The higher transmission risk patterns for both Loca and Twenke during the second part of the year is in agreement with the mean number of malaria cases reported by the Health Center of Maripasoula (Figure $5)$.

\section{Discussion}

Malaria transmission in French Guiana occurs mostly along the Maroni River (Figure 1) from where $77.2 \%$ of the cases were reported between 1999 and 2003. The region of Maripasoula represents the second most important focus with 


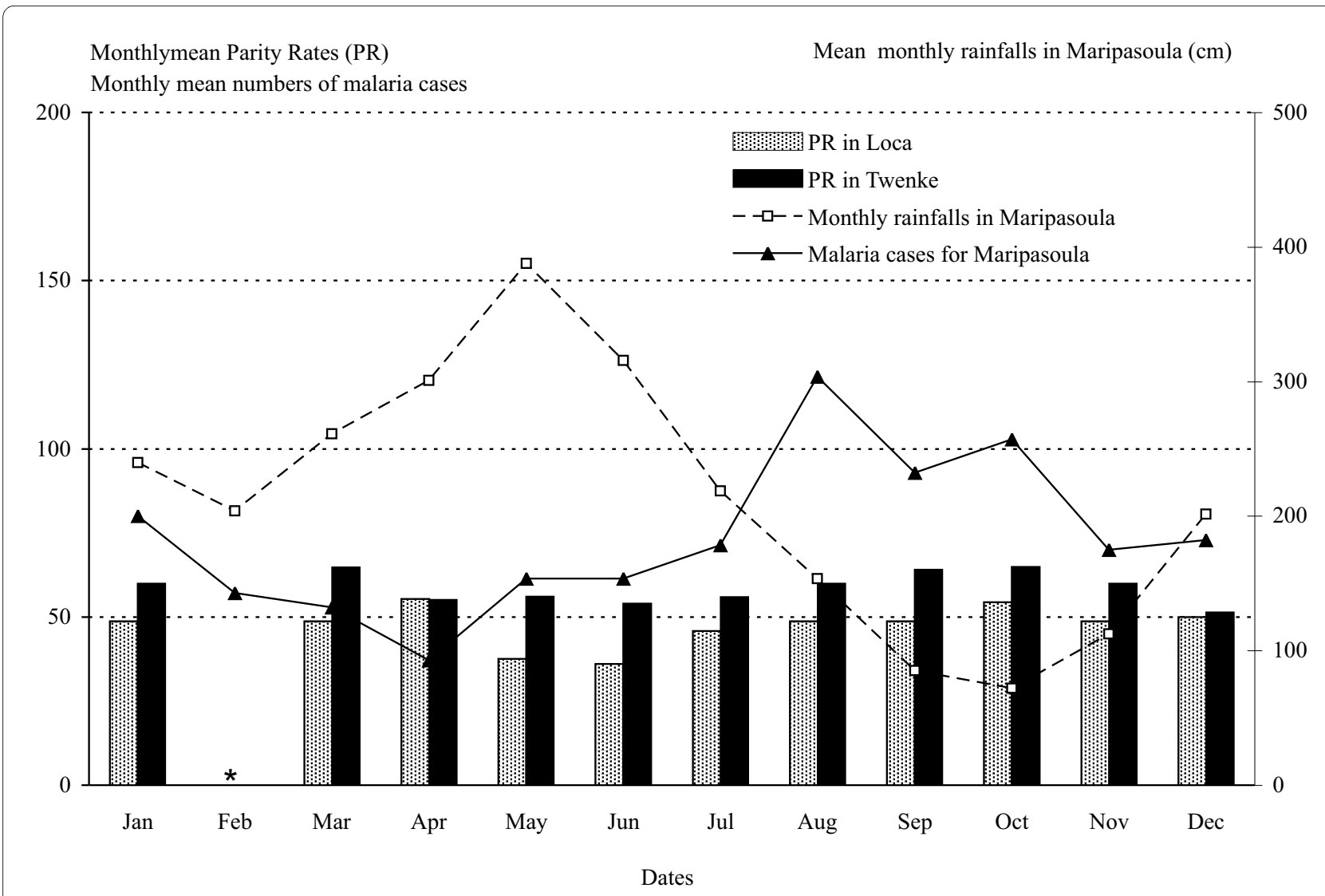

Figure 5 Monthly means Parity Rates. Monthly means An. darlingi PR (Parity Rates) in Loca and Twenke, and fluctuations of the mean monthly rainfalls in Maripasoula and the mean monthly number of malaria cases reported from Maripasoula. No captures were done for the months of February ${ }^{*}$ ).

$28.5 \%$ of cases [11]. The transmission peaks from August to October and $44 \%$ of the cases are reported from July to October. The peak of malaria cases occurs during the dry season when An. darlingi HBR are low (Figure 2) as already observed in the upper Amerindian villages [18] and the lower Maroni basin [19] but also in the western Brazilian Amazon [36]. At the opposite, the peak of malaria cases reported during the same months in the Venezuelan Amazonian region [37] is concomitant with the rainy season and the peaks of mosquito biting numbers [38]. These observations indicate that Anopheline HBR is fluctuating with the rains or the river levels $[39,40]$ and may not be the most important factor in the malaria transmission risk. In all locations, it is interesting to note that the peaks of malaria cases are found during the hottest months.

The mean entomological inoculation rate (EIR) of about 10 infected bites per person and per year in Loca is in the range of the EIR reported in the same area [19], but the value found in the Amerindian village is lower than reported before [18], that may indicate strong annual variations. In the other Amazonian countries, EIR has a comparable mean value of 10 infective bites/person/year in Rondônia (Brazil) [41] and in Venezuela [37]. But, in those countries, the EIR is also varying from 1.65 positive bites/ person/per in Roraima (Brazil) [42] to 129 infective bites/ person/year in Upper Orinoco (Venezuela) [38].

Anopheles darlingi is one of the most important malaria vector in South-America [43] and the most important vector in the Amazons [44]. Numerous studies were conducted on the population biology and genetics of An. darlingi showing the great heterogeneity between populations from different countries for both important behavioral determinants [45] and genetic markers [46,47]. The biting behaviour is varying from uni-modal to tri-modal and biting peaks were found for almost each hour between 6:00 PM and 6:00 AM [43]. When malaria control relies on protecting the people from mosquito bites, it appears impossible to give general recommendations against the species An. darlingi. As an example, the impregnated bed-nets will give little protection when the biting peak is between 7:00 PM and 9:00 PM as in Bolivia [48] or between 8:00 and 9:00 PM as in Peru [49], and at the opposite will be very useful when the biting peak is at 11:00 PM as in Surinam [17], at 1:00 AM as in Venezuela [38], or between 1:00 AM and 2:00 AM as in coastal French Guiana [13]. Moreover, all mosquito populations under comparisons were originated from locations 


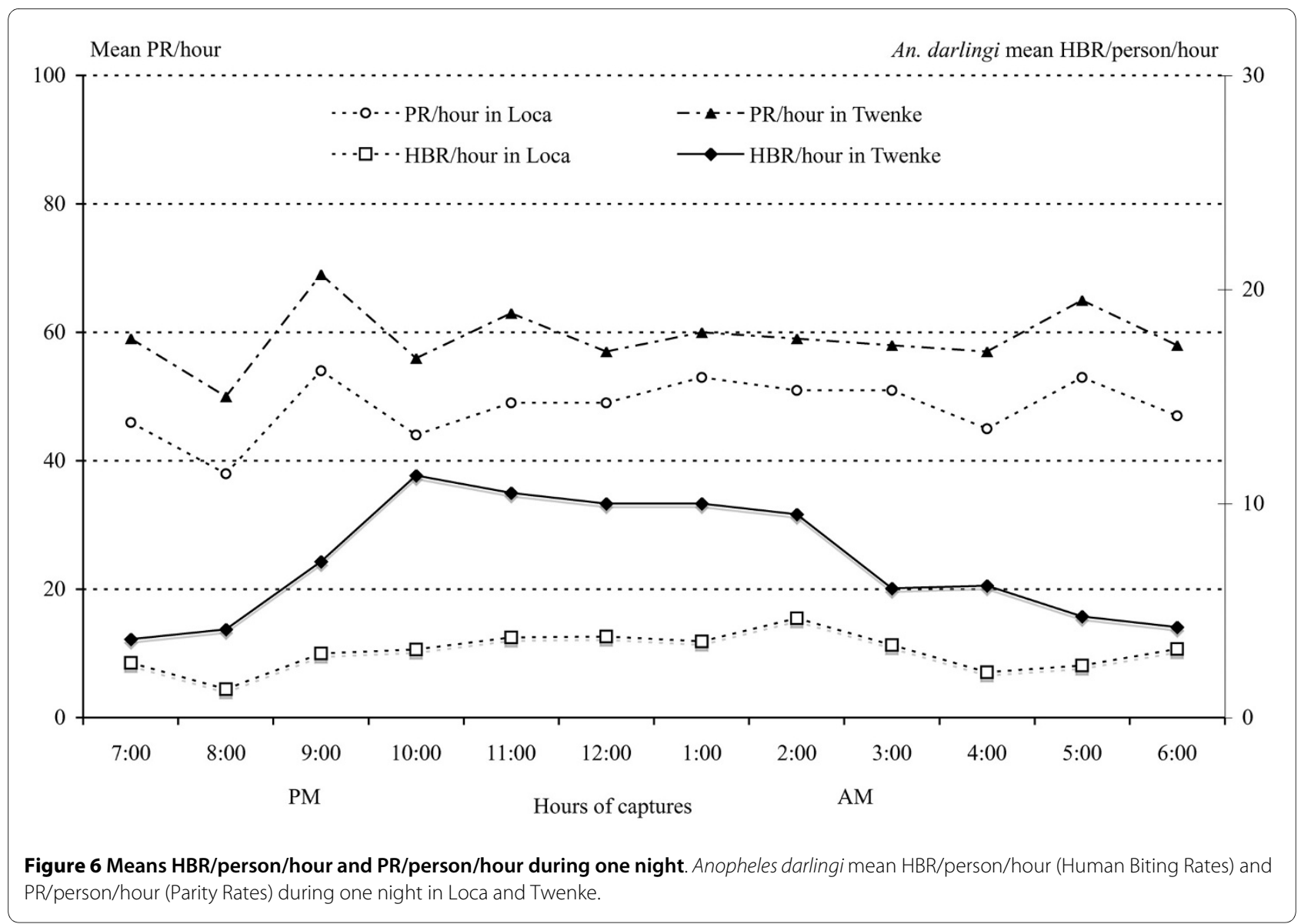

separated by long distances, and the genetic differences in such populations can be attributed to a geographical isolation [50]. In this study, the An. darlingi populations are almost sympatric with no natural barriers between the populations (Figure 1), and nevertheless show different bionomics patterns. The monthly and hourly biting patterns and even the malaria transmission risk periods are significantly different (Table 1). No genetic studies of the mosquitoes have already been performed, but future research should be done in this direction, to find out if these behaviour differences are due to ecological conditions, including the cultural differences between the villages (ethnic origin, housing, way of living, etc...) and/or if the differences are due to the presence of An. darlingi sub-species in the same region.

For the first time in French Guiana, entomological parameters could be related to the malaria transmission patterns. The peak of malaria cases occurring during the dry season is concomitant with the peak in the number of infected mosquitoes surviving enough to transmit (IMT) (Figure 7). This variable is unusual but was chosen to avoid the necessary approximations used in the estimation of the vectorial capacity. The IMT needs four variables and three of them can be extracted from field data, and take into account the mosquito density with the HBR, the survival with the PR, the infection rate and the duration of the extrinsic incubation period (EIP). This last parameter is depending on the temperatures [33,34] and higher temperatures found in French Guiana during the dry season from July to October lead to a shorter EIP duration. Although a reduced mosquito survival has been reported for higher temperatures [51], the mosquito survival estimated from the parity rates is not significantly different along the year. The shorter EIP will cause an increase in the IMT number, and consequently in the transmission risks.

\section{Conclusion}

The entomological investigations carried out in the two villages belongings to two different ethnic groups show clearly that the malaria transmission patterns are strongly different in the year and in the nights according to the location of the village. The numbers of infected mosquitoes surviving enough to transmit peaks in August and is concomitant with the peak of malaria cases and could be thus considered as an indicator of the transmission risk. The results presented herein will help to better understand and estimate the malaria transmission risks along the Maroni River of French Guiana, and must be used to develop better 


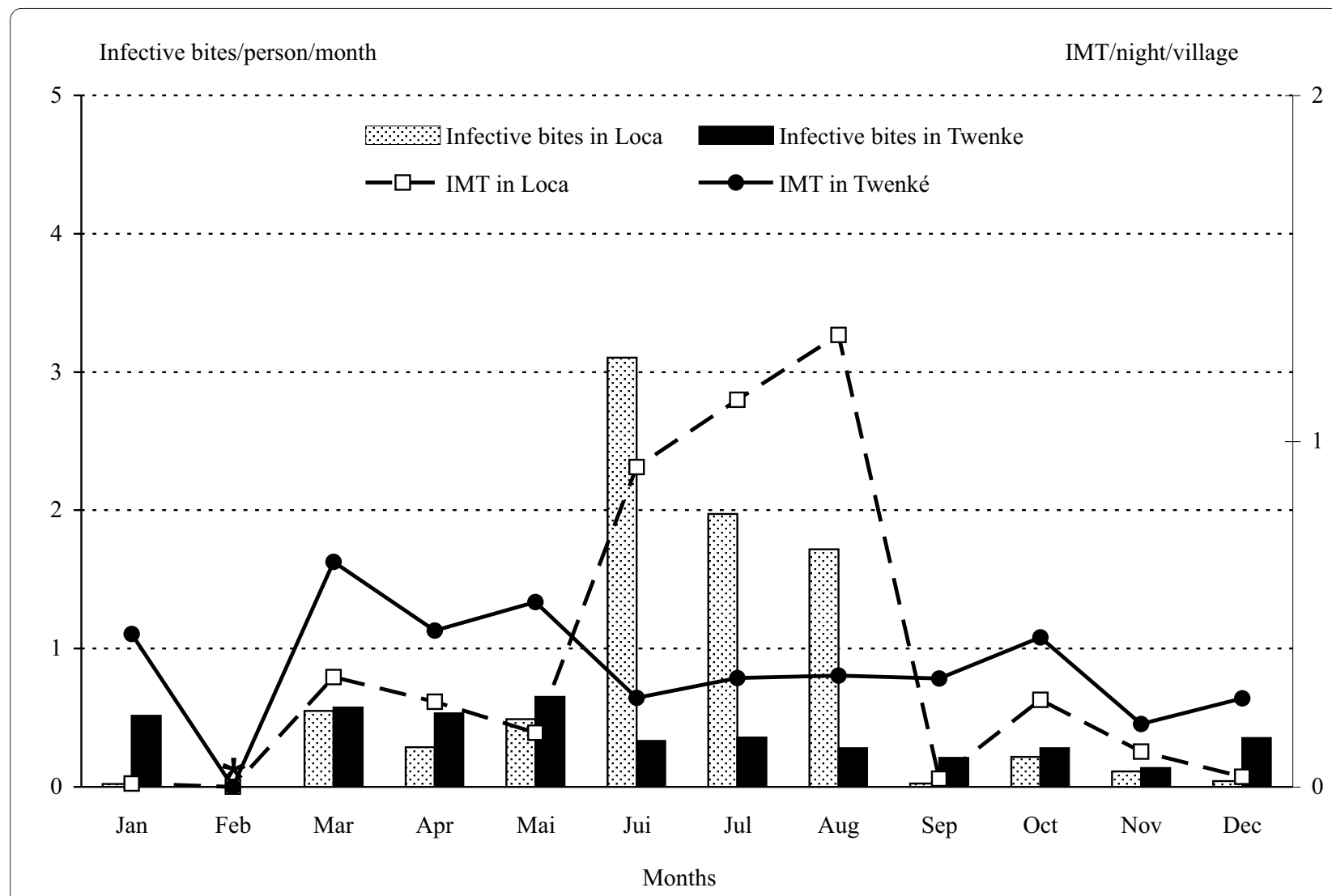

Figure 7 Monthly means of IB/person and IMT/night/village. Anopheles darlingi monthly means of IB/person (Infective Bites) and of IMT/night/ village (Infected Mosquitoes surviving enough to Transmit) in Loca and Twenke. No data were available for the months of January and February in Loca, and February in Twenke (*).

malaria prevention and vector control measures. The actions implemented in the two villages, and more largely in the two ethnic regions must integrate the differences including both cultural habits and mosquito behavior. More precisely, in the village of Loca, malaria transmission peaks from June to August and is much lower from October to May. Consequently, it can be recommended to focus the vector control efforts during the summer months. The transmission risk is also more important during the second part of the night. Because people are living in wooden houses, some practical vector control measures could be housespraying, fixing of impregnated insect screen to windows and doors, recommendation to use repellents for activities during the second part of the night and, above all, distribution of impregnated bed-nets. In the village of Twenke, the transmission risk remains very high all year long. Consequently, malaria prevention and vector control must be maintained regularly all year round and eventually reinforced during the dry season. The transmission risk is higher during the first part of the night and because the people are living in houses with only one or two walls, the impregnated mosquito bed-nets is the almost exclusive option for the children. For the adults, usually meeting outside during this first part of the night, without protection, the recommendation to use repellents may not be followed (for cultural reasons). Very few options are thus remaining to protect the population, except the use of mass prophylaxis.

Finally, vector studies coupled with epidemiological studies $[52,53]$ are the only approach to propose solutions to prevent, as much as possible, malaria transmission in inland French Guiana. The studies on the behaviour of An. darlingi in French Guiana indicate that further investigations on this species are needed, in particular genetic studies, to better understand the differences between the populations at the local and regional level. The use of this knowledge will result in the improvement of malaria prevention in French Guiana and more widely in the Amazons. 




Figure $8 \mathrm{IB} /$ person/hour and IMT/hour/village during one year. Anopheles darlingi numbers of IB/person/hour (Infective Bites) and of IMT/village/ hour (Infected Mosquitoes surviving enough to Transmit) during one year in Loca and Twenke.

\section{Additional material}

Additional file 1 Field and transformed data for HBR, PR, Infective Bites, IMT and statistical analysis. The data provided in a table (.xl format) with several sheets represent all detailed results on the mosquitoes collected during the two-year survey in the two villages of Loca and Twenké, as well as the results of the ELISA on individual mosquitoes and the estimates of Human Biting Rates (HBR), Parity Rates (PR), infective bites and Infected Mosquitoes surviving enough to Transmit (IMT) per month and per hour. The statistical analyses with the Kruskall-Wallis ANOVA are also reported in the Table.

\section{Competing interests}

The authors declare that they have no competing interests.

\section{Authors' contributions}

FF have made substantial contributions to the conception and design of the study, participated to the acquisition of data, carried out the analysis and interpretation of the data and was involved in the manuscript redaction. PG have made substantial contribution in the design of the study, the acquisition of the data, carried out the ELISA, and was involved in the verification of the data analysis and the critical revision of the manuscript. RC participated to the design of the study and the acquisition of the data. Jl have made substantial contribution in the acquisition of the data and logistics in field. RG was involved in data analysis and interpretation, in drafting the manuscript and revising it critically for important intellectual content. All authors read and approved the final manuscript.

\section{Acknowledgements}

The author's best thanks are due to Dr. Stéphane Laventure for his invaluable help, and Dr. Jean-Louis Sarthou, former Director of the Pasteur Institut of French Guiana for his complete support. We also thank the people collecting the mosquito on their legs, in particular Gabriel Fossé and Denis Aloiké, who both helped in the transportation, as well as the people of the villages of Loca and Twenké for their welcome and permission to perform the experiment in their villages. The authors also want to thank the people working within the Service Départemental de Désinfection, in particular Dr. Cathy Venturin and Roland Horth. The French Ministry of Health funded the study.

\section{Author Details}

'Institut Pasteur, Cellule d'Intervention Biologique d'Urgence (CIBU), 25-28, rue du Dr Roux, 75724 Paris cedex 15, France and 2Unité d'Entomologie Médicale, Institut Pasteur de Guyane, 23, Avenue Pasteur, BP 6010, 97300 Cayenne, French Guiana

Received: 30 November 2009 Accepted: 22 March 2010

Published: 22 March 2010

\section{References}

1. Carme B: Epidémiologie et diagnostic du paludisme en Guyane. Revue Francophone des Laboratoires 2005, 374:21-25.

2. Malaria in the Americas Data Tables (data from 2004 onwards) 2007 [http://www.paho.org/english/ad/dpc/cd/malaria.htm]. for the table "mal-americas-2007.pdf"

3. Raccurt CP: Paludisme, Anophèles, lutte anti-paludique en Guyane française: entre dogmatisme et discernement. Med Trop 1997, 57:401-406 
4. Carme B, Ardillon V, Girod R, Grenier C, Joubert M, Djossou F, Ravachol F: Update on the epidemiology of malaria in French Guiana. Med Trop 2009, 69:19-25.

5. Mouchet J, Nadiré-Galliot M, Gay F, Poman JP, Lepelletier L, Claustre J, Bellony S: Le paludisme en Guyane. II. Les caractéristiques des différents foyers et la lutte antipaludique. Bull Soc Path Exot 1989, 82:393-405.

6. Floch H: Antimalarial campaign in French Guiana. Bull World Health Organ 1954, 11:579-633.

7. Juminer B, Robin Y, Pajot FX, Eutrope R: Physionomie du paludisme en Guyane. Med Trop 1981, 41:135-146.

8. Esterre P, Cordoliani G, Germanetto P, Robin Y: Epidémiologie du paludisme en Guyane française. Bull Soc Path Exot 1990, 83:193-205.

9. Lepelletier L, Gay F, Nadiré-Galliot M, Poman JP, Bellony S, Claustre J, Traore BM, Mouchet J: Le paludisme en Guyane. I. Situation générale de l'endémie. Bull Soc Path Exot 1989, 82:385-392.

10. Carme B: Substantial increase of malaria inland areas of eastern French Guiana. Trop Med Int Health 2005, 10:154-159.

11. Chaud $P$, Paquet $C$, Huguet $P$, Cottrelle B: Surveillance épidémiologique du paludisme en Guyane Edited by: VS. CIRE Antilles-Guyane, Saint-Maurice; 2006

12. Annual Malaria Cases and Deaths in the Americas, 1998-2006 2006 [http://www.paho.org/english/ad/dpc/cd/mal-cases-deaths-19982006.pdf].

13. Pajot FX, Le Pont F, Molez JF, Degallier N: Agressivité d'Anopheles (Nyssorhynchus) darlingi Root, 1926 (Diptera, Culicidae) en Guyane française. Cahiers ORSTOM sér. Entomol Med Parasitol 1977, XV:15-22.

14. Claustre J, Venturin C, Nadiré M, Fauran P: Vecteurs de paludisme en Guyane française: étude dans un foyer épidémique proche de Cayenne (1989-1998). Bull Soc Path Exot 2001, 94:353-357.

15. Pajot FX, Molez JF, Le Pont F: Anophèles et paludisme sur le HautOyapock (Guyane française). Cahiers ORSTOM sér. Entomol Med Parasitol 1978, XVI:105-111

16. Roberts DR, Alecrim WD, Tavares AM, Radke MG: The, host-seeking and resting behavior of Anopheles darlingi in southeastern Amazonas, Brazil. J Am Mosa Control Assoc 1987, 3:433-341.

17. Rozendaal JA: Biting and resting behavior of Anopheles darlingi in the Suriname rainforest. J Am Mosa Control Assoc 1989, 5:351-358.

18. Girod R, Gaborit P, Carinci R, Issaly J, Fouque F: Anopheles darlingi bionomics and transmission of Plasmodium falciparum, Plasmodium vivax and Plasmodium malariae in Amerindian villages of the UpperMaroni Amazonian forest, French Guiana. Mem Inst Oswaldo Cruz 2008, 103:702-710.

19. Hiwat H, Issaly J, Gaborit P, Somai A, Samjhawan A, Sardjoe P, Soekhoe T, Girod R: Behavioral heterogeneity of Anopheles darlingi (Diptera: Culicidae) and malaria transmission dynamics along the Maroni River, Suriname, French Guiana. Trans R Soc Trop Med Hyg 2010, 104:207-213.

20. WHO: Malaria entomology and vector control. Learner's Guide World Health Publications, Geneva; 2003.

21. Detinova TS: Age-grouping methods in Diptera of medical importance. Ser World Health Organ 1962, 47:13-191.

22. Wirtz RA, Burkot TR, Graves PM, Andre RG: Field evaluation of enzymelinked immunosorbent assays for Plamodium falciparum and Plasmodium vivax sporozoites in mosquitoes (Diptera: Culicidae) from Papua New Guinea. J Med Entomol 1987, 24:433-487.

23. Coz J, Gruchet H, Chauvet G, Coz M: Estimation du taux de survie chez les Anophèles. Bull Soc Path Exot 1961, 54:1353-1358.

24. Ree HI, Hwang UW: Comparative study on longevity of Anopheles sinensis in malarious and non-malarious areas in Korea. Korean J Parasitol 2000, 38:263-266.

25. Charlwood DJ, Alecrim WA: Capture-recapture studies with the south American malaria vector Anopheles darlingi, Root. Ann Trop Med Parasitol 1989, 83:569-576.

26. Dos Santos RLC, Forattini OP, Burattini MN: Laboratory and field observations on duration of gonotrophic cycle of Anopheles albitarsis s.l. (Diptera: Culicidae) in southeastern Brazil. J Med Entomol 2002 39:926-930

27. Macdonald G: The epidemiology and control of malaria Oxford University Press, London; 1957.

28. Garrett-Jones C, Grab B: Bull World Health Organ 1964, 31:71-86.

29. Dye C: Vectorial capacity: Must we measure all its components. Parasitol Today 1986, 2:203-209.
30. Smith DL, McKenzie FE: Statics and dynamics of malaria infection in Anopheles mosquitoes. Malar J 2004, 3:13.

31. Teklehaimanot HD, Schwartz J, Teklehaimanot A, Lipsitch M: Weatherbased prediction of Plasmodium falciparum malaria in epidemic-prone regions of Ethiopia I. Patterns of lagged weather effects reflect biological mechanisms. Malar J 2004, 12:41.

32. Zucker JR: Changing patterns of autochthonous malaria transmission in the United States: a review of recent outbreaks. Emerg Infect Dis 1996, 2:37-43.

33. Kruskal WH, Wallis WA: Use of ranks in one criterion analysis of variance. J Amer Statist Assoc 1952, 52:583-621.

34. Zar JH: Biostatistical Analysis Second edition. Prentice Hall, Englewood Cliffs, New Jersey; 1984.

35. Mann HB, Whitney DR: On a test whether one or two random variables is stochastically larger than the other. Ann Math Statist 1947, 18:50-60

36. Camargo LM, dal Colletto GM, Ferreira MU, Gurgel Sde M, Escobar AL, Marques A, Krieger H, Camargo EP, da Silva LH: Hypoendemic malaria in Rondonia (Brazil, western Amazon region): seasonal variation and risk groups in an urban locality. Am J Trop Med Hyg 1996, 55:32-8.

37. Rubio-Palis Y, Wirtz RA, Curtis CF: Malaria entomological inoculation rates in western Venezuela. Acta Trop 1992, 52:167-174.

38. Magris M, Rubio-Palis Y, Menares C, Villegas L: Vector bionomics and malaria transmission in the Upper Orinoco river, southern Venezuela. Mem Inst Oswaldo Cruz 2007, 102:303-311.

39. Rozendaal JA: Relations between Anopheles darlingi breeding habitats, rainfall, river level and malaria transmission rates in the rain forest of Suriname. Med Vet Entomol 1992, 6:16-22.

40. Gil LH, Tada MS, Katsuragawa TH, Ribolla PE, da Silva LH: Urban and suburban malaria in Rondônia (Brazilian Western Amazon) II. Perennial transmissions with high anopheline densities are associated with human environmental changes. Mem Inst Oswaldo Cruz 2007, 102:271-276.

41. Gil LH, Alves FP, Zieler H, Salcedo JM, Durlacher RR, Cunha RP, Tada MS, Camargo LM, Camargo EP, Pereira-da-Silva LH: Seasonal malaria transmission and variation of anopheline density in two distinct endemic areas in Brazilian Amazonia. J Med Entomol 2003, 40:636-641.

42. Silva-Vasconcelos A, Kató MY, Mourão EN, de Souza RT, Lacerda RN, Sibajev A, Tsouris P, Póvoa MM, Momen H, Rosa-Freitas MG: Biting indices, host-seeking activity and natural infection rates of anopheline species in Boa Vista, Roraima, Brazil from 1996 to 1998. Mem Inst Oswaldo Cruz 2002, 97:151-161.

43. Zimmerman RH: Ecology of malaria vectors in the Americas and future directions. Mem Inst Oswaldo Cruz 1992, 87:371-383.

44. Deane LM: Malaria studies and control in Brazil. Am J Trop Med Hyg 1988, 38:223-230

45. Charlwood JD: Biological variation in Anopheles darlingi Root. Mem Inst Oswaldo Cruz 1996, 91:391-398.

46. Conn JE: Systematics and population level analysis of Anopheles darlingi. Mem Inst Oswaldo Cruz 1998, 93:647-650.

47. Mirabello L, Conn JE: Molecular population genetics of the malaria vector Anopheles darlingi in Central and South America. Heredity 2006, 96:311-321.

48. Harris AF, Matias-Arnéz A, Hill N: Biting time of Anopheles darlingi in the Bolivian Amazon and implications for control of malaria. Trans R Soc Trop Med Hyg 2006, 100:45-47.

49. Turell MJ, Sardelis MR, Jones JW, Watts DM, Fernandez R, Carbajal F, Pecor $J E$, Klein TA: Seasonal distribution, biology, and human attraction patterns of mosquitoes (Diptera: Culicidae) in a rural village and adjacent forested site near Iquitos, Peru. J Med Entomol 2008, 45:1165-1172

50. Conn JE, Vineis JH, Bollback JP, Onyabe DY, Wilkerson RC, Póvoa MM Population structure of the malaria vector Anopheles darlingi in a malaria-endemic region of eastern Amazonian Brazil. Am J Trop Med Hyg 2006, 74:798-806.

51. Kirby MJ, Lindsay SW: Effect of temperature and inter-specific competition on the development and survival of Anopheles gambiae sensu stricto and An. arabiensis larvae. Acta Trop 2009, 109:118-23.

52. Hustache S, Nacher M, Djossou F, Carme B: Malaria risk factors in Amerindian children in French Guiana. Am J Trop Med Hyg 2007, 76:619-625. 
53. Guthmann JP, Llanos-Cuentas A, Palacios A, Hall AJ: Environmental factors as determinants of malaria risk. A descriptive study on the northern coast of Peru. Trop Med Int Health 2002, 7:518-525.

doi: $10.1186 / 1475-2875-9-80$

Cite this article as: Fouque et al., Annual variations in the number of malaria cases related to two different patterns of Anopheles darlingi transmission potential in the Maroni area of French Guiana Malaria Journal 2010, 9:80

Submit your next manuscript to BioMed Central and take full advantage of:

- Convenient online submission

- Thorough peer review

- No space constraints or color figure charges

- Immediate publication on acceptance

- Inclusion in PubMed, CAS, Scopus and Google Scholar

- Research which is freely available for redistribution

Submit your manuscript at www.biomedcentral.com/submit
() BioMed Central 